
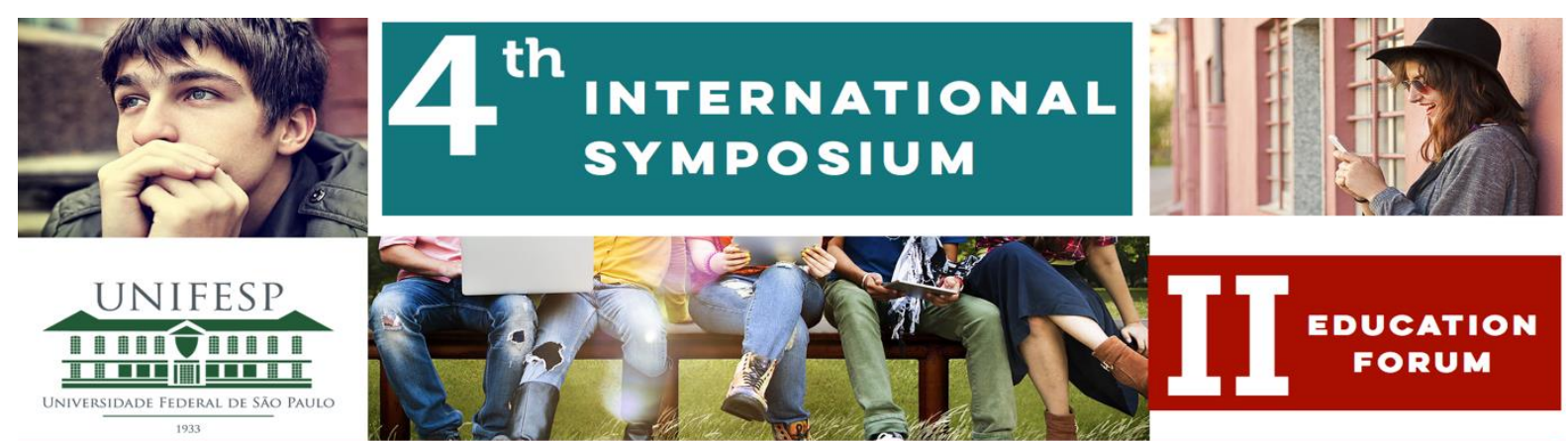

Adolescence(s): Vulnerabilities, Protagonisms and Challenges

PRÁTICAS DE EDUCAÇÃO EM SAÚDE PARA ADOLESCENTES: REVISÃO NARRATIVA DA LITERATURA

\title{
HEALTH EDUCATION PRACTICES FOR ADOLESCENTS: NARRATIVE LITERATURE REVIEW
}

DOI: https://doi.org/10.22388/2525-5894.2018.0055

Grasiella Bueno Mancilha - Doutoranda do Programa de Pós-Graduação em Educação e Saúde na Infância e na Adolescência - UNIFESP. grasiella.mancilha@gmail.com

Carla Ferraz - Professora da Faculdade Santa Marcelina.

Bruno de Oliveira Pinheiro - Doutorando do Programa de Pós-Graduação em Educação e Saúde na Infância e na Adolescência - UNIFESP. pinheiro.bruno10@hotmail.com

Denise De Micheli - Professora Adjunta do Departamento de Psicobiologia - UNIFESP. demicheli.unifesp@gmail.com

Trabalho de Conclusão de Curso da Pós-Graduação em Saúde da Família da Faculdade Santa Marcelina. Produção do grupo de pesquisa CIENSEA - Centro Interdisciplinar de Estudos em Neurociência, Saúde e Educação na Adolescência

\section{Resumo}

Objetivo do estudo é conhecer quais, como e onde se dão as ações educativas em saúde destinada aos adolescentes e quais são seus os principais resultados encontrados por esses estudos, destacando quais são os direcionamentos das estratégias de educação em saúde aos adolescentes. A coleta dos dados foi realizada por meio de uma consulta informatizada no banco de dados bibliográficos. Para identificação dos artigos, foram utilizados os descritores: "educação em saúde" AND adolescente AND uso de drogas. A amostra é composta por 10 artigos científicos, publicados de 2014 a 2018, na língua portuguesa, online, disponíveis na íntegra. Os resultados foram tabulados e a discussão apresentada a partir de categorias temáticas: Características dos adolescentes e dos locais das intervenções; Estratégias utilizadas; Temáticas trabalhadas e Profissionais envolvidos nas intervenções. As ações de Educação em Saúde para adolescência utilizaram-se de metodologias ativas buscando a construção coletiva, onde o adolescente é valorizado e estimulado a participar ativamente, capaz de analisar criticamente sua realidade e ser capaz de transformar sua realidade. Está presente a visão moralizante, principalmente diante do uso de drogas, que está sendo percebida e desconstruída. Há espaço 
para novas ações de educação em saúde, principalmente para espaços para além do escolar, e que os próprios adolescentes possam ser multiplicadores de ações educativas em saúde.

Palavras-chave: educação em saúde, adolescente, uso de drogas.

\begin{abstract}
The objective of the study is to know the health education actions for adolescents and the main results of these studies, highlighting the direction of health education strategies for adolescents. Data collection was done through a computerized consultation in the bibliographic database. To identify the articles, the descriptors were used: "health education" AND teenage AND drug use. The sample is composed by 10 scientific articles, published from 2014 to 2018, in the Portuguese language, online, available in full. The results were tabulated and the discussion presented from thematic categories: Characteristics of the adolescents and the sites of the interventions; Strategies used; Subjects worked and Professionals involved in the interventions. The actions of Health Education for adolescence used active methodologies seeking collective construction, where the adolescent is valued and encouraged to participate actively, able to critically analyze their reality and be able to transform their reality. Moralizing vision is present, especially in the face of drug use, which is being perceived and deconstructed. There is room for new actions in health education, especially for spaces other than school, and adolescents themselves can be multipliers of educational actions in health.
\end{abstract}

Key-words: health education, adolescent, drug use.

\title{
INTRODUÇÃO
}

A adolescência é um período na vida, que na sociedade contemporânea, assumem importantes recortes e construções sociais complexas. (1-3).

Há discussões acerca da adolescência em diversas dimensões, como a biológica - atuação de hormônios, desenvolvimento e amadurecimento dos órgãos genitais e até mesmo do cérebro, que no adolescente ainda não completou seu amadurecimento e desenvolvimento; dimensão psicológica - marcada pela construção de identidade que se manifesta pela busca de um grupo de amigos aos quais se identifica, e também pelas experimentações e intensidades de suas vivências, nas relações interpessoais, amizades e interesse sexual. É na dimensão social que a vivência da adolescência assume contornos singulares, pois influencia e é influenciada pelas condições sociais e econômicas, pelo contexto em que vive, ou seja, o adolescente da periferia terá acesso e vivências relacionadas ao meio que o cerca, assim como um adolescente de classe média alta, outras condições e formas de viver a adolescência. Assim, podemos nomear e considerar aspectos semelhantes e diferentes na experiência da adolescência, sendo mais condizente chamá-las de "adolescências". (3)

As condições sociais que envolvem o adolescente necessitam ser compreendidas para que as intervenções a serem planejadas, considerem a realidade singular, para que estejam alinhadas às suas reais necessidades e modos de viver.

Os modos de viver dos adolescentes compreendem aspetos do seu estilo de vida e comportamento, ou seja, como organizam sua rotina, seus hábitos alimentares, modos de vestir e de se comunicar, locais que frequentam, pessoas que se relacionam e a forma que o fazem, que tipo de música, filme e programas culturais e de lazer gostam ou praticam, entre outros. $(1,3,4)$. 
Os comportamentos decorrentes de seu estilo de vida, entremeado por seu contexto de vida, possui grande importância para a elaboração de ações de saúde. Dentre esses possíveis comportamentos, os relacionados ao uso de drogas lícitas ou ilícitas, sexualidade e violência; são temáticas que se destacam no cenário educativo em saúde.

O levantamento nacional de saúde do escolar, (5) mais especificamente o relacionado ao uso de álcool e drogas, apresentam números crescentes de adolescentes que fazem o uso cada vez mais precocemente de álcool e outras drogas.

A educação em saúde no Brasil diante da população de adolescentes é um desafio, principalmente relacionado ao uso de álcool e outras drogas. Programas Ministeriais de prevenção ao uso de drogas elegem a escola como local privilegiado para que essas ações aconteçam. Mesmo o Programa de Saúde da Escola (PSE) criado pelo decreto no 6286 de 2007, que preconiza ações que articulem a saúde e a educação, que atuem considerando o contexto escolar e social. Essas ações devem compreender ações de promoção, prevenção e assistência à saúde do escolar.(6).

O paradigma biomédico, com enfoques nas orientações em saúde pautados por condutas normalizadoras e prescritivas são suficientes para engajar o adolescente no que tange o cuidado de si? Quais são as estratégias mais utilizadas por profissionais a essa população e quais são os profissionais envolvidos nessas ações? Quais são os espaços em que essas ações acontecem? Quais os temas mais recorrentes destinados a essa população? Quais as características sociais e econômicas dos adolescentes a que são destinadas essas ações de educação em saúde?

Há desafios importantes a serem debatidos e implementados acerca das formas de fazer as ações destinadas a uma população que muitas vezes não está nos serviços de saúde. Conhecer o que o nosso país vê implementando nessa área foi nossa motivação principal para a elaboração dessa revisão.

\section{JUSTIFICATIVA}

As adolescências e suas construções sociais contemporâneas têm caracterizado uma variedade de singularidades e como desdobramentos a necessidade de ampliação do olhar diante de como oferecer práticas de saúde a essa população.

Buscando maior efetividade e alinhamento das práticas em saúde com os modos de viver dos adolescentes, é necessária a compreensão e reflexão que compõem as construções dos fenômenos sociais, como as adolescências.

Ao compreender a variabilidade dos diferentes determinantes sociais que permeiam o fenômeno da adolescência, os profissionais da saúde poderão alinhar seus planejamentos e ações para o cuidado com os sujeitos individuais e coletivos que representam as adolescências.

Mas o quanto as adolescências são compreendidas enquanto plurais? O quanto os contextos sociais e econômicos que permeiam os adolescentes, os influenciam e são influenciados por eles, são discutidos e analisados? Como é ser adolescente em um bairro de periferia de uma metrópole? Como é ser adolescente em um bairro de classe média alta em uma capital? Esses adolescentes são iguais? Serão semelhantes em alguns aspectos, porém muito diferentes em outros, pois os determinantes sociais que os permeiam são diferentes, impactando de diferentes formas seus modos e estilos de vida. Quais são as situações sociais e culturais que vulnerabilizam os adolescentes? Para além de recortes etários, de ciclo de vida - puberdade e transformações 
psicológicas; o adolescente é singular, é um sujeito de direito que deve ter espaços de expressão, em que sua voz seja escutada e seus desejos e angustias - acolhidos. A importância de respeitar a igualdade que o valoriza e lutar contra a diferença que o inferioriza.

Refletindo e questionando sobre a assistência de saúde aos adolescentes, algumas perguntas foram pensadas: Qual o espaço para o cuidado do adolescente no sistema de saúde? Onde os adolescentes podem acessar informações sobre saúde? Quais são as estratégias e práticas de saúde implementadas a essa população? Quais são as principais necessidades e demandas vivenciadas pelos adolescentes na atualidade? Como a atenção básica em saúde sistematiza suas ações e práticas voltadas a essa população? Quais são as diretrizes do Ministério da Saúde voltadas aos adolescentes? Essas diretrizes consideram as adolescências em sua pluralidade?

Muitas demandas acerca de necessidades que homogeneízam a adolescência veem logo a nossa mente quando pensamos acerca das necessidades que eles devam ter - como: orientações acerca da sexualidade, gravidez na adolescência, infecções sexualmente transmissíveis e uso de drogas. Essas necessidades são validadas pelos próprios adolescentes?

Sobre o uso de drogas, consideramos que há inúmeras situações em que direta ou indiretamente permeiam esse uso e a manutenção dele.

Por avaliarmos que muitos determinantes sociais permeiam essa problemática, optamos em um campo extremamente complexo, pesquisar acerca de quais intervenções de educação em saúde estão sendo implementadas aos adolescentes no Brasil e quais são as características e locais onde acontecem.

Diante desse conjunto de indagações, incrementadas pelo interesse da pesquisadora diante do tema adolescências e práticas de educação em saúde e uso de drogas, realizamos essa pesquisa.

\section{OBJETIVO}

Realizar revisão da literatura a fim de conhecer quais, como e onde se dão as ações educativas em saúde destinada aos adolescentes e quais são seus os principais resultados encontrados por esses estudos.

Conhecer e destacar quais são os direcionamentos das estratégias de educação em saúde aos adolescentes.

\section{METODOLOGIA}

Este é um estudo exploratório de revisão da literatura de abordagem qualitativa, com recorte transversal.

De acordo com (7), as pesquisas exploratórias são desenvolvidas com vistas a proporcionar uma visão geral do problema, característica que possibilita atender ao objetivo deste estudo. A pesquisa bibliográfica tem como objetivo proporcionar maior familiaridade com o problema, com vistas a torná-lo mais explícito ou a constituir hipóteses.

Os critérios para inclusão foram apresentar a temática de educação em saúde junto aos adolescentes em formato de intervenção educativa acerca de temáticas sobre saúde. 
A coleta dos dados foi realizada por meio de uma consulta informatizada no banco de dados bibliográficos Scielo (Scientific Eletronic Library Online) e BVS Adolec - Biblioteca Virtual de Saúde na área de adolescentes.

Os descritores utilizados nesta pesquisa foram consultados na lista de descritores em Ciências da Saúde (DECs), com o objetivo de utilizar os termos adequados para a pesquisa bibliográfica. Para identificação dos artigos, foram utilizados os DeCS: "educação em saúde" and adolescente and uso de drogas. Também se utilizou os mesmos termos como palavras-chave na BVS- Adolec.

Definição das informações a serem extraídas dos estudos selecionados/ categorização dos estudos. $\mathrm{Na}$ etapa subsequente, foram selecionados os artigos de interesse para este estudo, considerando-se como critérios: artigos da área da saúde, ser um trabalho desenvolvido em âmbito nacional; ter sido publicado nos últimos 5 (cinco) anos; estar disponível na íntegra em português online, abordar no resumo e/ou no título características e/ou aspectos sobre: intervenção educativa com adolescentes onde a problemática do uso de drogas aparecesse direta ou indiretamente.

A partir dessa busca, realizou-se uma leitura exploratória que se constitui na verificação dos resumos com a finalidade de selecionar os artigos relacionados ao objeto de estudo.

Diante de uma amostra de 50 artigos na Scielo e 10 na BVS Adolec foram selecionados 10 deles após a leitura dos títulos e resumos que contemplaram os critérios de inclusão.

Avaliação dos estudos incluídos na revisão, realizado a leitura na íntegra de todos os artigos incluídos, realização de tabulação dos principais dados de cada um dos artigos. Após a interpretação dos resultados. Análise e síntese dos resultados encontrados. Como última etapa, a apresentação da revisão/síntese do conhecimento.

\section{RESULTADOS}

A amostra é composta por 10 artigos científicos, na língua portuguesa, online, disponíveis na íntegra e que abordem a temática: educação em saúde destinada aos adolescentes. Os artigos foram apresentados considerando o ano de sua publicação, do mais recente para o mais antigo conforme especificado no Quadro 1. 
Quadro 1 - Descrição dos artigos localizados na base de dados SciELO (Scientific Eletronic Library Online) e BVSAdolec; segundo autor principal, ano de publicação, objetivos e considerações.

\begin{tabular}{|c|c|c|}
\hline TÍTULO/AUTOR/ANO & OBJETIVOS & CONSIDERAÇÕES \\
\hline $\begin{array}{l}\text { 1. Ações Educativas para a } \\
\text { sensibilização de um estilo de vida mais } \\
\text { saudável em adolescentes } \\
\text { Vieiro VSF; Farias JM, } 2017 \text {. }\end{array}$ & $\begin{array}{l}\text { Analisar a aquisição de conhecimentos } \\
\text { após ações de educação em saúde } \\
\text { sobre alimentação saudável, atividade } \\
\text { física e educação postural na } \\
\text { sensibilização de um estilo de vida mais } \\
\text { saudável de adolescentes matriculados } \\
\text { em duas escolas públicas do município } \\
\text { de Criciúma, Santa Catarina. }\end{array}$ & $\begin{array}{l}\text { A pesquisa investigou o aumento de conhecimento após as } \\
\text { intervenções educativas, destacando aquelas com os } \\
\text { melhores resultados. Não se investigou quais foram às } \\
\text { repercussões no comportamento dos adolescentes } \\
\text { referente aos temas abordados, por exemplo, se constatou } \\
\text { um aumento de conhecimentos acerca da temática sobre } \\
\text { atividade física e não se alterou o nível de atividade física } \\
\text { praticado diariamente. Destacam que educação em saúde } \\
\text { realizada em âmbito escolar foi efetiva para aumentar os } \\
\text { conhecimentos dos adolescentes referentes ao estilo de } \\
\text { vida saudável. Defendem que as pequenas ações são } \\
\text { importantes no sentido de contribuir para mudanças no } \\
\text { estilo de vida mais saudável. }\end{array}$ \\
\hline $\begin{array}{l}\text { 2. Pesquisa-ação } \\
\text { emancipatória com jovens escolares: } \\
\text { relato de experiência. } \\
\text { Oliveira E; Soares CB; Silva JA, } 2016 \text {. }\end{array}$ & $\begin{array}{l}\text { Relatar a experiência de utilização de } \\
\text { pesquisa-ação emancipatória (PAE) com } \\
\text { jovens de modo a expor suas } \\
\text { potencialidades para problematizar a } \\
\text { realidade dos participantes. Construir } \\
\text { com os jovens uma programação } \\
\text { midiática de educação sobre drogas. }\end{array}$ & $\begin{array}{l}\text { A PAE possibilitou participação e diálogo efetivo dos } \\
\text { adolescentes. Problematização e crítica da realidade } \\
\text { vivenciada, utilização da linguagem de preferência e de } \\
\text { domínio dos adolescentes. } \\
\text { Recomendações de que as estratégias educativas que } \\
\text { envolvam os jovens sejam realizadas através de mídias } \\
\text { variadas, pois eles utilizam diferentes formas de } \\
\text { comunicação, e que as mensagens educativas sejam curtas, } \\
\text { provocativas e questionadoras. Além de utilização de } \\
\text { músicas do seu universo cultural que tragam visões críticas } \\
\text { e que fale da importância da participação política deles. }\end{array}$ \\
\hline $\begin{array}{l}\text { 3. Educação em Saúde na prevenção do } \\
\text { HIV/AIDS com homens jovens usuários } \\
\text { de crack } \\
\text { Pinto ACS, et al, } 2016\end{array}$ & $\begin{array}{l}\text { Promover um espaço crítico-reflexivo } \\
\text { acerca da prevenção do HIV/AIDS com } \\
\text { jovens usuários de crack. }\end{array}$ & $\begin{array}{l}\text { O estudo possibilitou um espaço de reflexões e busca de } \\
\text { soluções para as situações vividas. Os jovens traçaram uma } \\
\text { proposta preventiva ao uso de drogas aos adolescentes } \\
\text { escolares, que ainda não tiveram contato com o uso de } \\
\text { drogas (o produto dessa produção não foi apresentado no } \\
\text { artigo). }\end{array}$ \\
\hline TÍTULO/AUTOR/ANO & OBJETIVOS & CONSIDERAÇÕES \\
\hline $\begin{array}{l}\text { 4. Drogas na Escola: análise das vozes } \\
\text { sociais em jogo } \\
\text { Barros e Colaço, } 2015\end{array}$ & $\begin{array}{l}\text { Analisar vozes sociais em jogo na } \\
\text { produção de sentidos sobre drogas } \\
\text { entre adolescentes. }\end{array}$ & $\begin{array}{l}\text { Os adolescentes representaram vozes sociais de cunho } \\
\text { proibicionista, mas também houve momentos em que } \\
\text { questionaram as práticas de educação em saúde, } \\
\text { corriqueiras destinadas a eles, de forma a se reposicionar. } \\
\text { o espaço do grupo focal se configurou um espaço de } \\
\text { tensão entre vozes sociais arraigadas culturalmente pelas } \\
\text { ideias do proibicionismo (reiteração dos valores) e a } \\
\text { ressignificação de tais valores. }\end{array}$ \\
\hline $\begin{array}{l}\text { 5. Concepções sobre drogas por } \\
\text { adolescentes escolares } \\
\text { Filho EAF, et al.,2015 }\end{array}$ & $\begin{array}{l}\text { Conhecer as concepções dos } \\
\text { adolescentes escolares sobre drogas } \\
\text { dentro de um contexto social. }\end{array}$ & $\begin{array}{l}\text { Os grupos focais foram relevantes, estimularam a } \\
\text { participação dos adolescentes nas discussões de temas de } \\
\text { importância e interesse deles. O conhecimento foi limitado } \\
\text { por parte dos adolescentes, apresentaram uma visão } \\
\text { negativa, reprodutores da visão construída pela sociedade }\end{array}$ \\
\hline
\end{tabular}




\begin{tabular}{|c|c|c|}
\hline & & $\begin{array}{l}\text { e pela mídia, por isso necessitam de intervenções } \\
\text { educativas nos diversos contextos em que vivem: escolar, } \\
\text { social e familiar, visando minimizar as vulnerabilidades a } \\
\text { que estão expostos. }\end{array}$ \\
\hline $\begin{array}{l}\text { 6. Violência sob o olhar de } \\
\text { adolescentes: intervenção educativa } \\
\text { com Círculo de Cultura } \\
\text { Neto WB et al, } 2015\end{array}$ & $\begin{array}{l}\text { Aplicar a metodologia Círculo de Cultura } \\
\text { junto a adolescentes escolares como } \\
\text { estratégia de educação em saúde pelo } \\
\text { enfermeiro acerca da temática } \\
\text { violência. }\end{array}$ & $\begin{array}{l}\text { A estratégia de Círculo de Cultura foi eficaz junto ao } \\
\text { adolescente, pois favoreceu condições para reconhecerem } \\
\text { os aspectos que permeiam a produção e reprodução das } \\
\text { violências. Processo ensino-aprendizagem mútuos, aos } \\
\text { enfermeiros (que foram facilitadores dos círculos) quanto } \\
\text { aos adolescentes, ambos incrementaram seu } \\
\text { empoderamento no processo de conscientização. Exercício, } \\
\text { por parte dos enfermeiros, de se despir de preconceitos } \\
\text { estereotipados dos adolescentes, abrindo-se a perceber } \\
\text { um momento de oportunidades e que podem ser } \\
\text { protagonistas de suas vidas. } \\
\text { Limitações do estudo foi o número reduzido da amostra em } \\
\text { um contexto específico de vulnerabilidade. }\end{array}$ \\
\hline $\begin{array}{l}\text { 10. Limites e Potencialidades das rodas } \\
\text { de conversa no cuidado em saúde: uma } \\
\text { experiência com jovens no sertão } \\
\text { nordestino } \\
\text { Sampaio J. et al, } 2014\end{array}$ & $\begin{array}{l}\text { Contribuir com a qualificação } \\
\text { metodológica e pedagógica das rodas } \\
\text { de conversa. }\end{array}$ & $\begin{array}{l}\text { Espaço das rodas de conversa como potência, em } \\
\text { oportunizar aos adolescentes um espaço para ser } \\
\text { escutadas, estar aberto ao inesperado, às ideias } \\
\text { divergentes e a ideias transformadoras que envolvam a } \\
\text { promoção de saúde. Rodas de conversa como estratégias } \\
\text { pedagógico-transformadoras. }\end{array}$ \\
\hline
\end{tabular}

\section{DISCUSSÃO}

Após a tabulação e analise dos artigos, organizamos os achados de forma a agrupá-los didaticamente, para melhor discussão e compreensão dos achados.

Apresentaremos as seguintes categorias: Características dos adolescentes e dos locais das intervenções; Estratégias utilizadas; Temáticas trabalhadas e Profissionais envolvidos nas intervenções.

\section{- Características dos adolescentes e dos locais das intervenções}

As características destacadas na maioria dos artigos são que as ações foram destinadas aos adolescentes escolares de ensino fundamental e médio, residentes em áreas de periferia, com altos índices de violência, acesso às drogas, encontrando-se em diversas situações de vulnerabilidade.

As ações de educação de saúde privilegiaram a escola como local das intervenções, há nessa escolha uma influência do processo histórico do desenvolvimento de ações de educação em saúde. Dois dos dez estudos analisados trazem diferentes locais de ação educativa em saúde $(8,9)$. A comunidade terapêutica, local destinado ao tratamento de jovens que já possuíam prejuízos decorrentes do uso de crack; e uma comunidade no sertão pernambucano, onde os encontros aconteceram em diversos locais, como na igreja e na escola, respectivamente.

A prevalência de estudos que aconteceram nas escolas nos sinaliza um limite das propostas de educação em saúde, pois há outros lugares potencialmente férteis às essas intervenções junto aos adolescentes, como no território e comunidade em que vivem. Esse achado coloca em pauta a necessidade de realização de novas pesquisas em outros locais frequentados pelos adolescentes para além do ambiente escolar. 
Além disso, as ações possuem limites, pois atingem somente os adolescentes matriculados e frequentando a escola, deixando de contemplar adolescentes ainda mais vulneráveis que não estavam frequentando a escola, e que poderiam se beneficiar de ações educativas em saúde a serem desenvolvidas em outros locais, como instituições de acolhimento de adolescentes, espaços de convivência e cultura juvenil, entre outros. Essas ações podem ser desenvolvidas intersetorialmente.

\section{- Estratégias utilizadas}

Os estudos trouxeram, em sua maioria metodologias qualitativas. Somente dois estudos, apresentaram análises estatísticas envolvendo a aquisição de conhecimentos após intervenção educativa pontual. Viero et al. (2017) e Viero et al. (2015) Esse tipo de estudo possui limites importantes, pois adquirir novos conhecimentos acerca de determinada temática não garante que esses adolescentes modificaram os seus comportamentos. Essas considerações foram pautadas como limites dos estudos pelos autores de tais estudos.

Círculos de cultura, rodas de conversa e oficinas foram as principais estratégias, todas evidenciam a utilização de metodologias ativas que pressupõem e valorizam a participação ativa dos adolescentes.

Valorizaram e defenderam que o adolescente se interessa mais por estratégias diversificadas, que utilizem de recursos audiovisuais, como filmes, músicas, dramatizações e uso de fotografias que eles mesmos tiraram a partir de um direcionamento dos facilitadores.

O envolvimento proporcionou mais chances de engajamento dos adolescentes. Essas estratégias foram potentes em oportunizar o despertar de alguns adolescentes diante da complexidade de suas realidades, despertando também olhares mais críticos e empoderados.

As oficinas desvelaram o que ainda predomina na concepção dos adolescentes acerca das temáticas abordadas, uma dessas oficinas, discutindo o tema de uso de drogas, os adolescentes elaboraram uma dramatização que apresentou uma adolescente que após uma briga com a mãe, combina de sair para uma festa com amigos e nesta festa faz uso de droga. Durante a festa, a adolescente ouve duas vozes, uma denominada voz do "bem", que diz para não usar drogas e a voz do "mal" que dizia para usar mesmo. A discussão pautou uma visão extremista e moralizante por parte dos adolescentes, observada através do comportamento do adolescente que na dramatização "desobedece" a voz do "bem" - simbolizada para eles como a voz da mãe ou da família e que acompanha a voz do "mal" representada pelas amizades. Caracterizando uma visão estereotipada de um adolescente desobediente, que busca nas drogas a solução para seus problemas e é influenciada pelos pares em detrimento "a voz" da família. Em outro momento, os mesmos adolescentes, diante de um jogo de perguntas e respostas (elaboradas por eles) discutiram sobre a frase "evite o primeiro gole vale para todos, ou só para aqueles que são viciados". Os adolescentes defenderam que evitar o primeiro gole era o melhor a fazer em todos os casos, imperando a ideia de abstinência total preconizado pelas ideias do proibicionismo. (12)

A importância de diversas estratégias lúdicas é um destaque (13) para estimular o envolvimento e interesse do adolescente para além do momento do encontro presencial, como, criação de grupo em rede social para ampliar a interação entre os participantes para além dos espaços das oficinas. Os adolescentes confeccionaram um painel da região, utilizando fotos (tirada por eles) dos locais que circulavam na comunidade, elaboração de jornais que continham as necessidades da região, assistiram filme para disparar debates, audição e elaboração de músicas como rap e funk relacionadas as temáticas trabalhadas, produção de desenhos em quadrinhos e criação de roteiro para um programa de rádio que abordava questões relacionadas a periferia e quanto ao uso de drogas. 
Houve uma participação dos adolescentes envolvidos na intervenção, para isso as autoras reforçam que "é necessário diálogo, influência mútua e o projeto a ser desenvolvido deve fazer sentido ao jovem". Mudanças significativas ocorreram, observadas através de ações mais conscientes e críticas, que são capazes de transformar a realidade em que vivem diferentemente de percepções apenas de replicação de um discurso moralista permeado pelo modelo de guerra as drogas, o qual precisa ser superado, para avançarmos nas ações que privilegiem ações educativas que estejam alinhadas com as estratégias de redução de danos, diretrizes da atual política nacional de álcool e drogas.

Destacamos a metodologia ativa do círculo de cultura, preconizada por Paulo Freire, que possuí como principais aspectos, a valorização e a troca do saber popular através do diálogo, que ao refletir sobre a realidade, os participantes tenham a oportunidade de olhar com outros olhos, a partir das reflexões e novas construções do conhecimento grupal, possibilitando a ação no intuito de modificar as realidades vivenciadas. Entendendo esses sujeitos como capazes de serem protagonistas de suas histórias. (14)

As conclusões de autores (8) que indicam que é importante a criação de um espaço onde tenha oportunidade ao novo e às ideias divergentes, que realmente seja um momento reflexivo que conduza para além de ações normatizadoras e prescritivas de comportamentos, o famoso "faça assim", que muitas vezes vêm carregados ideias moralistas e preconceituosas, limitando reflexões mais enriquecedoras acerca do "porque tem que ser assim?".

Pesquisadores sinalizam que as estratégias de educação em saúde aos adolescentes precisam considerar uma aproximação prévia ao contexto vivenciado por eles, buscando conhecer seu universo vocabular, além de permitir aproximação e criação de vínculo, e que também as ações sejam criativas e atrativas a eles, que considerem diversas formas de linguagem audiovisuais e estratégias baseadas nas metodologias ativas.

\section{- Temáticas trabalhadas}

Mesmo ao utilizar como uma das palavras-chave o "uso de drogas", por se tratar de uma temática complexa, que envolve diversas dimensões relacionadas ao modo de viver, encontramos estudos que realizaram intervenções educativas que envolveram também os temas sobre violência, sexualidade, direitos reprodutivos, além de aspectos relacionados à promoção de saúde, como alimentação saudável, saúde bucal, atividade física e educação postural.

Dois estudos realizados $(15,16)$ utilizaram o Círculo de Cultura, como metodologia de educação em saúde, implementada por enfermeiros em uma escola de rede estadual de ensino localizada em uma região vulnerável, com altos índices de homicídio e tráfico de drogas.

Ações educativas que abordaram as temáticas: saúde bucal, prevenção ao uso de drogas e sexualidade aplicadas por residentes das áreas de odontologia, enfermagem e psicologia do programa multiprofissional da Universidade do Extremo Sul Catarinense. Foi aplicado um questionário pré e pós a intervenção. Os encontros aconteceram uma vez por mês. Envolveu adolescentes de 11 a 17 anos que cursavam o ensino fundamental II ou o ensino médio. Houve diferença na amostra de cada uma das temáticas, saúde bucal (108), prevenção ao uso de drogas (105) e sexualidade (99) participantes. Os encontros foram ministrados pelos residentes que privilegiaram uma metodologia dialógica, troca de experiências e reflexões. Esses estudos não apresentaram dados qualitativos sobre a participação dos adolescentes, não falou da estrutura de cada encontro nem tempo de duração. Sobre quem conduziu cada encontro, disseram que cada um dos responsáveis pelo tema elaborou oito questões objetivas do conteúdo ministrado.(10)

Estudo do mesmo autor (11), agora abordando temáticas alimentação saudável, atividade física e educação postural, demonstrou quanto à aquisição de conhecimentos (medidos por instrumento de múltipla 
escolha antes e após a intervenção) ser efetivo aos adolescentes, porém ressaltam que por não haver acompanhamento longitudinal não saberão se esses conhecimentos irão repercutir em comportamento protetivo.

A concepção moralista, de cunho proibicionista, encontradas nos estudos $(12,17)$ onde os próprios adolescentes replicam o discurso social de que a melhor forma de prevenir é a abstinência total. Este é o pano de fundo que permeia a visão dos adolescentes sobre a temática do uso de drogas, cenário este, que limita a discussão dos cenários atuais que envolvem a complexidade do fenômeno do uso de drogas, alinhados com a proposta da política nacional de álcool e outras drogas, a Redução de Danos, que requer destes adolescentes um papel de protagonista e uma leitura mais crítica do contexto social, econômico e político. Os próprios adolescentes trouxeram uma visão estereotipada do "ser adolescente" - como um rebelde que é facilmente influenciado pelas amizades.

Uma possibilidade de uma visão diferente acerca da discussão da temática de drogas na escola,(13) relata a experiência em uma escola pública, na periferia de São Paulo com 13 estudantes de 15 a 17 anos (9 homens e 4 mulheres), através de oficinas (13 encontros) com cerca de 2 horas de duração cada. As treze oficinas foram organizadas em cinco fases interligadas 1) fase exploratória (4 encontros): com o intuito de identificar o problema, além de ser uma fase em que os primeiros contatos com os participantes acontece; 2 ) fase de concretizar o tema - problematizar; 3) fase de planejamento e encaminhamento de respostas aos problemas, onde ocorreu uma instrumentalização teórica e prática aos participantes (fase 2 e 3 ocorreram em cinco oficinas); 4) fase de expressão de novos conhecimentos e monitoramento da PAE e 5) fase de expressão da nova síntese, fusão do saber formal com o informal, apropriando-se do novo saber (fase 4 e 5 aconteceram em quatro oficinas). Assim, como resultados, encontraram jovens que puderam refletir sobre o uso de drogas inserido em algo maior acerca dos modos de viver diante da maior criticidade diante da realidade vivenciada por eles na periferia da capital paulista.

\section{- Profissionais envolvidos nas intervenções}

A maioria dos profissionais envolvidos nas ações de saúde foram os próprios pesquisadores, identificamos a participação de enfermeiros (maioria dos estudos), psicólogos, dentista, educadores físicos e nutricionistas. Um dos estudos destacou que a ação foi realizada na comunidade e que envolveu outros atores sociais e profissionais, da saúde e educação, em uma ação intersetorial, como por exemplo, educadores e agentes comunitários de saúde. (8)

\section{CONSIDERAÇÕES FINAIS}

As ações de Educação em Saúde para adolescência revelaram que há importantes avanços quanto à forma de implementar junto aos adolescentes uma construção coletiva, onde seja valorizado e estimulado a sua participação ativa, realmente o vendo como um ser singular e como um sujeito de direitos, capaz de analisar criticamente sua realidade e ser capaz de transformar sua realidade.

O uso de drogas como temática complexa e relacionada a temáticas como violência e comportamento sexual. A presença marcante de discurso proibicionista pelos adolescentes e por alguns autores sinalizaram a necessidade de avanço nas formas de lidar com a temática na perspectiva da redução de danos e de formas mais acolhedoras e inclusivas de todos, principalmente daqueles adolescentes que já possuem uso de drogas problemático. Que sejam construídos espaços seguro e de acolhimento das diversas formas de viver, sem julgamentos e visão moralizadora. Que os adolescentes tenham a oportunidade de construir uma visão crítica diante da realidade que os cercam, de forma que possam se sentirem capazes de transformar as realidades vivenciadas, como protagonistas e empoderados. 
As intervenções apresentadas nos estudos, em sua maioria, utilizaram de metodologias ativas, onde considerou a importância de envolvimentos dos adolescentes em espaços acolhedores e que estes fossem estimulados ao protagonismo, utilizando de ferramentas pedagógicas lúdicas, como música, vídeos, dramatizações, fotos; mediados por estímulo ao diálogo e em uma relação de horizontalidade com os mediadores e facilitadores das ações educativas.

Os estudos revelaram uma predominância de ações em espaços escolares, o que chama a atenção para importância de ampliação e diversificação dos cenários, sobretudo para incluir os adolescentes que o ensino formal não conseguiu captar e manter.

Os estudos, em sua maioria também representaram experiências pontuais, realizados pelos próprios pesquisadores, o que nos revela uma baixa capilaridade dessas ações em diferentes cenários, contando também com o próprio adolescente para ser um agente multiplicador de ações educativas em saúde, apostando na efetividade de uma educação por pares e por lideranças juvenis.

\section{REFERÊNCIAS}

DAYRELL, J. O jovem como sujeito social. Rev Bras Educ [Internet]. 2003 [cited 2018 Jun 4];24. Available from: http://www.scielo.br/pdf/\%0D/rbedu/n24/n24a04.pdf

HELENA T, ABRAMO, W. DÁVILA, León O. Juventude e adolescência no Brasil: referências conceituais. 2005 [cited 2018 Jun 4]; Available from: http://library.fes.de/pdf-files/bueros/brasilien/05623.pdf

OZELLA, S. MARIA, W. de A. J. DESMISTIFICANDO A CONCEPÇÃO DE ADOLESCÊNCIA. 2008 [cited 2018 Jun 4];38(133):97-125. Available from: http://www.scielo.br/pdf/cp/v38n133/a05v38n133.pdf

MOREIRA, A.; VÓVIO, C. L.; DE MICHELI D. Prevenção ao consumo abusivo de drogas na escola: desafios e possibilidades para a atuação do educador Drug abuse prevention in school: challenges and possibilities for the role of the educator. Educ Pesqui [Internet]. 2015 [cited 2018 Jun 4];41(1):119-35. Available from: http://dx.doi.org/10.1590/S1517-97022015011670

PENSE [Internet]. 2015 [cited 2018 Jun 4]. Available from: https://biblioteca.ibge.gov.br/visualizacao/livros/liv97870.pdf

BRASIL. Brasil. 2007 [cited 2018 Jun 4]; Available from: http://portal.mec.gov.br/index.php?option=com_docman\&view=download\&alias=1726-saudenaescoladecreto6286-pdf\&category_slug=documentos-pdf\&Itemid=30192

GIL, A. Métodos e Técnicas de Pesquisa Social [Internet]. 2008 [cited 2018 Jun 4]. Available from: https://ayanrafael.files.wordpress.com/2011/08/gil-a-c-mc3a9todos-e-tc3a9cnicas-de-pesquisa-social.pdf

SAMPAIO, J. SANTOS, G. C. AGOSTINI, M. SALVADOR, A. de S. Limites e potencialidades das rodas de conversa no cuidado em saúde: Uma experiência com jovens no sertão pernambucano. Interface Commun Heal Educ. 2014;18:1299-312.

PINTO, A.C.S. QUEIROZ, M.V.O. GUBERT, F. do A. BRAGA. V.A.B. PINHEIRO, P.N. da C. Educação em saúde na prevenção do HIV/AIDS com homens jovens usuários de crack. Texto e Context Enferm. 2016;25(3):1-9. 
VIERO, V. dos S.F. FARIAS. J.M. de, FERRAZ. F. SIMÕES, P.W. MARTINS, J.A. CERETTA, L.B. Health education with adolescents: analysis of knowledge acquisition on health topics. Esc Anna Nery - Rev Enferm [Internet]. 2015;19(3):484-90. Available from: http://www.gnresearch.org/doi/10.5935/1414-8145.20150064

DOS, V, Ferreira Viero $S$, Joni E, De F. M. EDUCATIONAL ACTIONS FOR AWARENESS OF A HEALTHIER LIFESTYLE IN ADOLESCENTS AÇÕES EDUCATIVAS PARA A SENSIBILIZAÇÃO DE UM ESTILO DE VIDA MAIS SAUDÁVEL DE ADOLESCENTES. J Phys Educ v [Internet]. 2017 [cited 2018 Apr 26];28. Available from: http://www.scielo.br/pdf/jpe/v28/2448-2455-jpe-28-e2812.pdf

BARROS J. P. P, COLAÇO V. de F.R. Drogas na Escola: análise das vozes sociais em jogo. Educ Real. 2015;40(1):253-73.

OLIVEIRA E. et al.; Pesquisa-ação emancipatória com jovens escolares: relato de experiência. Rev Gaúcha Enferm [Internet]. 2016;37(3):1-6. Available from: http://www.scielo.br/scielo.php?script=sci_arttext\&pid=S1983-14472016000300801\&lng=pt\&tlng=pt

I WBN, A. et al. Violência sob o olhar de adolescentes : intervenção educativa com Círculos de Cultura. 2015;68(4):617-25.

BRANDÃO, N. et al.; Educational intervention on violence with adolescents: possibility for nursing in school context. Esc Anna Nery - Rev Enferm [Internet]. 2014;18(2):195-201. Available from: http://www.gnresearch.org/doi/10.5935/1414-8145.20140028

BRANDÃO, N. W. et al. Violência sob o olhar de adolescentes: intervenção educativa com Círculos de Cultura. Rev Bras Enferm [Internet]. 2015;68(4):617-25. Available from: http://www.scielo.br/scielo.php?script=sci_arttext\&pid=S0034-71672015000400617\&lng=pt\&tlng=pt

FARIA, F. E. A. et al. Perceptions of adolescent students about drugs. Rev Bras Enferm [Internet]. 2015;68(3):457-63, 517-23. Available from: http://www.scielo.br/scielo.php?script=sci_arttext\&pid=S0034-

71672015000300517\&lng=en\&nrm=iso\&tlng=pt 